\title{
Development of a Turnkey Hydrogen Fueling Station Final Report
}

\author{
For \\ State College, PA \\ Hydrogen Fueling Station
}

\author{
Submitted to: \\ United States Department of Energy
}

Submitted by:

Air Products and Chemicals, Inc.

July 17,2008

revised July 8, 2010 
David E. Guro (Primary Contact)

Air Products and Chemicals, Inc.

7201 Hamilton Boulevard

Allentown, PA 18195

Email: gurode@apci.com

Secondary Contacts:

Edward F. Kiczek:

Phone: (610) 481-4705

Email: kiczekef@airproducts.com

Kendra Gill:

Phone: (610) 467-4464

Email: gillks@airproducts.com

Othniel Brown:

Phone: (610) 481-1395

Email: browno@airproducts.com

DOE/GO Project Office: Carolyn Elam

Phone: (303) 275-4953;

Email: Carolyn.elam@go.doe.gov

DOE/HQ Project Officer: Arlene Anderson

Phone: (202) 586-3818

Email Arlene.anderson@hq.doe.gov

Cooperative Agreement

No. DE-FC36-02AL67613

(Formerly DE-FC04-02AL67613)

Contractor:

Air Products and Chemicals, Inc.

7201 Hamilton Boulevard

Allentown, PA 18195

Subcontractors:

H2Gen Innovations, Inc. - Alexandria, VA

Pennsylvania State University - University Park, PA

QuestAir Technologies Inc. - Burnaby, Canada (engineering)

Start Date: 01 January 2002

End Date: 27 September 2007 


\section{Disclaimer}

This report was prepared as an account of work sponsored by an agency of the United State Government. Neither the United States Government nor any agency thereof, or any of their employees, makes any warranty, express or implied, or assumes any legal liability or responsibility for the accuracy, completeness, or usefulness of any information, apparatus, product, or process disclosed or represents that its use would not infringe privately owned rights. Reference herein to any specific commercial product, process, or service by trade name, trademark, manufacturer, or otherwise does not necessarily constitute or imply its endorsement, recommendation or favoring by the United States Government or any agency thereof. The view and opinions of authors expressed herein do not necessarily state or reflect those of the United States Government or any agency thereof. 
TABLE OF CONTENTS

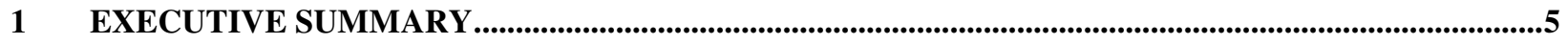

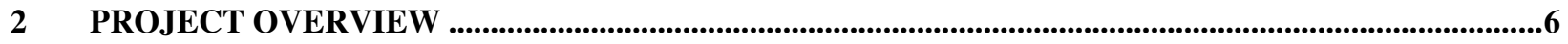

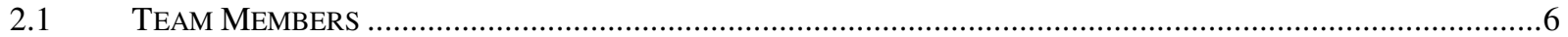

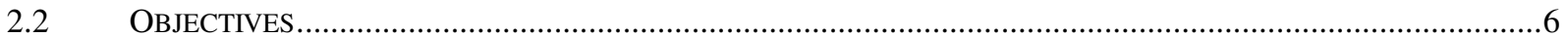

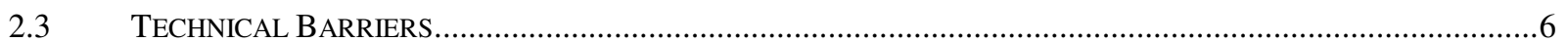

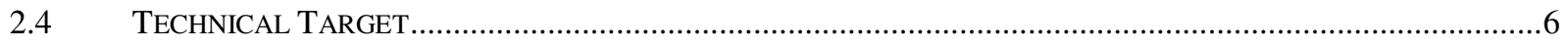

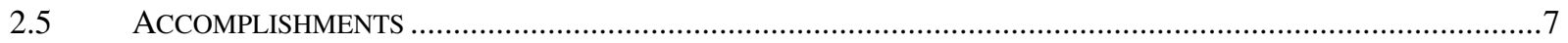

$3 \quad$ PROJECT ACTIVITY SUMMARY ...................................................................................................................

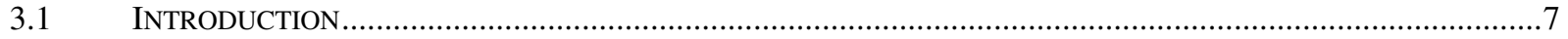

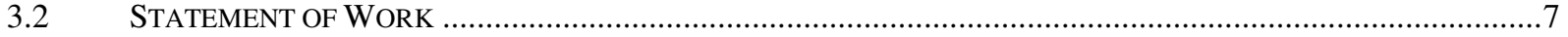

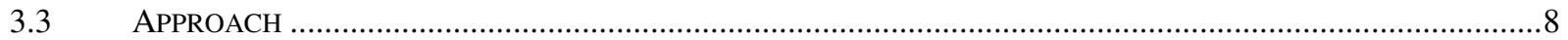

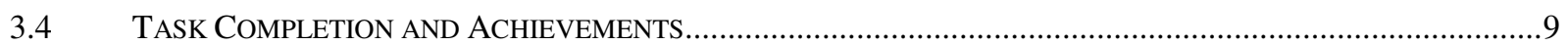

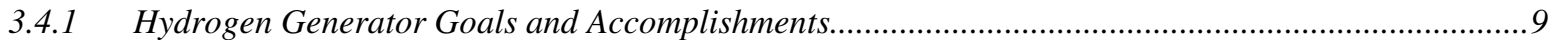

3.4.2 Compression and Storage Goals and Accomplishments........................................................... 14

3.4.3 Dispenser Goals and Accomplishments......................................................................................15

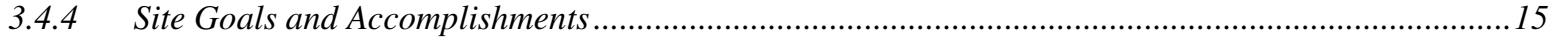

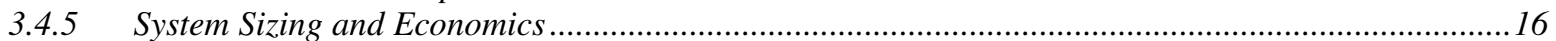

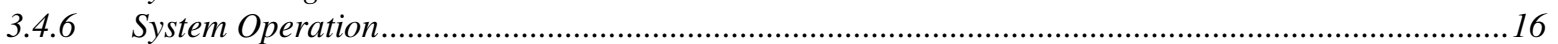

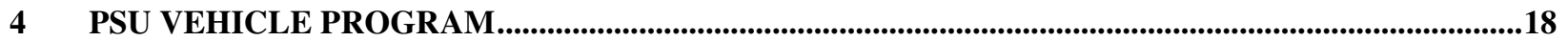

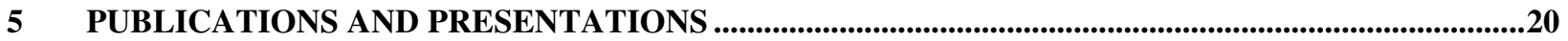

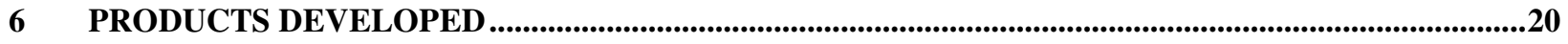

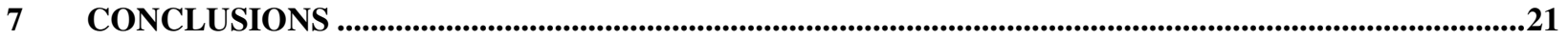




\section{Executive Summary}

The transition to hydrogen as a fuel source presents several challenges. One of the major hurdles is the cost-effective production of hydrogen in small quantities (less than $1 \mathrm{MMscf} /$ month). In the early demonstration phase, hydrogen can be provided by bulk distribution of liquid or compressed gas from central production plants; however, the next phase to fostering the hydrogen economy will likely include onsite generation and extensive pipeline networks to help effect a pervasive infrastructure. Providing inexpensive hydrogen at a fleet operator's garage or local fueling station is a key enabling technology for direct hydrogen Fuel Cell Vehicles (FCVs). The objective of this project was to develop a comprehensive, turnkey, stand-alone, commercial hydrogen fueling station for FCVs with state-of-the-art technology that is cost-competitive with current hydrocarbon fuels. Such a station would promote the advent of the hydrogen fuel economy for buses, fleet vehicles, and ultimately personal vehicles.

Air Products, partnering with the U.S. Department of Energy (DOE), The Pennsylvania State University, Harvest Energy Technology, and QuestAir, developed a turnkey hydrogen fueling station on the Penn State campus. Air Products aimed at designing a station that would have $65 \%$ overall station efficiency, $82 \%$ PSA (pressure swing adsorption) efficiency, and the capability of producing hydrogen at $\$ 3.00 / \mathrm{kg}(\mathrm{gge}) \mathrm{H}_{2}$ at mass production rates. Air Products designed a fueling station at Penn State from the ground up.

This project was implemented in three phases. The first phase evaluated the various technologies available in hydrogen generation, compression, storage, and gas dispensing. In the second phase, Air Products designed the components chosen from the technologies examined. Finally, phase three entailed a several-month period of data collection, full-scale operation, maintenance of the station, and optimization of system reliability and performance.

Based on field data analysis, it was determined by a proprietary hydrogen-analysis model that hydrogen produced from the station at a rate of $1500 \mathrm{~kg} / \mathrm{day}$ and when produced at 1000 stations per year would be able to deliver hydrogen at a price of $\$ 3.03 / \mathrm{kg}$ (gge) $\mathrm{H}_{2}$. The station's efficiency was measured to be $65.1 \%$, and the PSA was tested and ran at an efficiency of $82.1 \%$, thus meeting the project targets.

From the study, it was determined that more research was needed in the area of hydrogen fueling. The overall cost of the hydrogen energy station, when combined with the required plot size for scaled-up hydrogen demands, demonstrated that a station using steam methane reforming technology as a means to produce on-site hydrogen would have limited utility in the marketplace. Alternative hydrogen supplies, such as liquid or pipeline delivery to a refueling station, need to be included in the exploration of alternative energy site layouts. These avenues need to be explored before a definitive refueling station configuration and commercialization pathway can be determined. 


\section{PRODUCTS Y $\quad$ Development of a Turnkey $\mathrm{H}_{2}$ Fueling Station}

\section{Project Overview}

\subsection{Team Members}

The project team comprised Air Products, Harvest Energy Technology, Inc., Pennsylvania State University, and QuestAir Technologies.

\subsection{Objectives}

The turnkey hydrogen station project was designed to demonstrate the potential for an economically viable, stand-alone, fully integrated hydrogen fueling station based upon the reforming of natural gas by striving to:

- Develop a cost-effective solution to the reforming of natural gas to produce a reformate stream;

- Develop an efficient, cost-effective means to purify the hydrogen-rich reformate to pure hydrogen employing Pressure Swing Adsorption (PSA) technology;

- Develop an optimum system to compress, store, meter, and dispense hydrogen to fuel vehicles;

- Efficiently integrate the process steps mentioned above into a safe, userfriendly, cost-effective fueling station;

- Demonstrate the operation of the fueling station at Penn State University

- Maintain safety as the top priority in the fueling station design and operation;

- Obtain adequate operational data to provide the basis for future commercial fueling stations.

\subsection{Technical Barriers}

DOE Technical Barriers (identified in the "Hydrogen, Fuel Cells and Infrastructure Technologies Multiyear Program Plan," Section 3.5.4.2 - Technical Validation) addressed in this program are:

- Storage (fast fill)

- $\mathrm{H}_{2}$ Refueling Infrastructure (cost of $\mathrm{H}_{2}$; interface for fast fill)

- Maintenance \& Training Facilities (train personnel for $\mathrm{H}_{2}$ handling)

- Codes and Standards (lack of adopted codes \& standards)

\subsection{Technical Target}

DOE Targets (identified in the "Hydrogen, Fuel Cells and Infrastructure Technologies Multiyear Program Plan," Table 3.2.1 - Task 3) addressed in this program are:

- Develop ability to produce hydrogen on a scale-up basis for $\$ 3.00 / \mathrm{kg}$ in 2005

- Efficiency:

- Obtain an overall PSA efficiency of $82 \%$ by 2005.

- Achieve an overall station efficiency of $65 \%$. 


\section{PRODUCTS Y $\quad$ Development of a Turnkey $\mathrm{H}_{2}$ Fueling Station}

\subsection{Accomplishments}

The objectives of the turnkey hydrogen fueling station at Penn State's State College campus were achieved. The main highlights of the project include the following:

- Met DOE $\mathrm{H}_{2}$ PSA efficiency target of $82 \%$ for 2005 - lab and field testing

- Met DOE overall system efficiency target of $65 \%$ - start-up performance test

- Met DOE target of $\$ 3.00 / \mathrm{kg} \mathrm{H}_{2}$ dispensed - based on H2A calculation of $1500 / \mathrm{kg} /$ day and nth unit costs in mass production

- Operated the station successfully for 6 months

- Operated $\mathrm{H}_{2}$ generator at a production capacity of $50 \mathrm{~nm}^{3} / \mathrm{hr}$

\section{Project Activity Summary}

\subsection{Introduction}

The transition to hydrogen as a fuel source presents several challenges. One of the major hurdles is the cost-effective production of hydrogen in small quantities. In the early demonstration phase, hydrogen can be provided by bulk distribution of liquid or compressed gas from central production plants; however, the next phase to fostering the hydrogen economy will likely include onsite generation to help effect a pervasive infrastructure. Providing inexpensive hydrogen at a fleet operator's garage or local fueling station is a key enabling technology for direct hydrogen Fuel Cell Vehicles (FCVs). The objective of this project is to develop a comprehensive, turnkey, standalone, commercial hydrogen fueling station for FCVs with state-of-the-art technology that is cost-competitive with current hydrocarbon fuels. Such a station will promote the advent of the hydrogen fuel economy for buses, fleet vehicles, and ultimately personal vehicles.

\subsection{Statement of Work}

An outline of the tasks that composed each of the three project phases follows.

\section{Phase 1: Conceptual Design and Cost Estimation}

Task 1.1: Subsystems: Conceptual Design and Cost Estimates

Task 1.1.1: Reformer Design

Task 1.1.2: $\mathrm{H}_{2}$ Purifier

Task 1.1.3: Dispenser

Task 1.1.4: Siting

Task 1.1.5: Compression \& Storage

Task 1.2: System Integration and Final Cost Estimate

Task 1.3: Phase 1 Project Management and Reporting

\section{Phase 2: Subsystems R\&D}

Task 2.1: Reformer Catalyst Development

Task 2.1.1: Reformer Catalyst Proof of Concept Testing and Optimization Task 2.2: Reformer Development

Task 2.3: $\mathrm{H}_{2}$ Purifier Development 


\section{PRODUCTS 4 E. Development of a Turnkey $\mathrm{H}_{2}$ Fueling Station}

Task 2.3.1: $\mathrm{H}_{2}$ Purifier Adsorbent POC Testing and Optimization

Task 2.3.2: $\mathrm{H}_{2}$ Purifier System Development

Task 2.4: Dispenser Development

Task 2.5: Compression and Storage

Task 2.6: Phase 2 Project Management and Reporting

\section{Phase 3: Fabrication and Testing of Full-scale ( $B$ unit) Integrated System}

Task 3.1: Final System Design

Task 3.2: Site Preparation

Task 3.3: Fabrication and Pre-delivery Testing

Task 3.4: Delivery, Installation and Start-up

Task 3.5: Operations and Testing

Task 3.6: Phase 3 Project Management and Reporting

\subsection{Approach}

The development efforts of the fueling station were built on preliminary work accomplished by the major partners. As the overall project manager, Air Products was responsible for the total system integration and final development of the installed equipment. As the system integrator, Air Products ensured that the system was fully optimized and that all of the individual components were compatible to deliver the lowest cost hydrogen fuel. This project was managed in three phases, with Stage Gate reviews between each phase.

Phase 1 ran from October 2001 to May 2002, during which the subsystem conceptual designs were formulated and costs evaluated. Several options were developed and compared for the reformer, PSA system, compression, storage, and dispenser. Air Products worked with several reformer suppliers to develop and evaluate the applicability of autothermal reforming (ATR), partial oxidation of heavy oils (POX), and steam methane reforming (SMR) systems. At the end of Phase 1, Air Products confirmed the team's ability to reach the cost targets via an established definition of scope and execution costs. Air Products also chose the subsystem partners for further development of components in Phase 2.

From May 2002 to the fall of 2003, Phase 2 further developed the most promising subsystem designs assessed and selected in Phase 1. Laboratory and field testing of the hydrogen generation system, dispenser, compressor, and storage systems was carried out. Working with Harvest Energy Technology, Air Products' engineers optimized the design of the reformer for use in the hydrogen generator system. Air Products completed the design of the hydrogen and compressed natural gas-hydrogen blend dispensers, which were tested, installed, and commissioned on the Penn State fueling station site. Finally, Air Products served as the system integrator to pull together the various pieces of the station into a comprehensive turnkey unit, working on minimizing the total cost of delivered hydrogen at the same time.

During Phase 3, scale-up and detailed engineering design of all equipment was completed. The engineered system was analyzed for DFMA (Design for Manufacture and Assembly), and the assembled system included instrumentation for data collection 
and provisions for remote monitoring of operation. Fabrication of all equipment and installation at Penn State followed. The fueling station started up and was put into operation at Penn State in April 2006. The operating period was to be six months, but due to power outages and unforeseen equipment troubleshooting, the station operated 17 months. The last part of Phase 3 validated the cost of $\mathrm{H}_{2}$ delivered from the installed fueling station by running a model verified by a lab test that simulated scaled-up production of hydrogen at $1500 \mathrm{~kg} / \mathrm{day}$, including a study pertaining to the impact of mass-producing components.

The overall layout for the station is depicted in Figure 1.

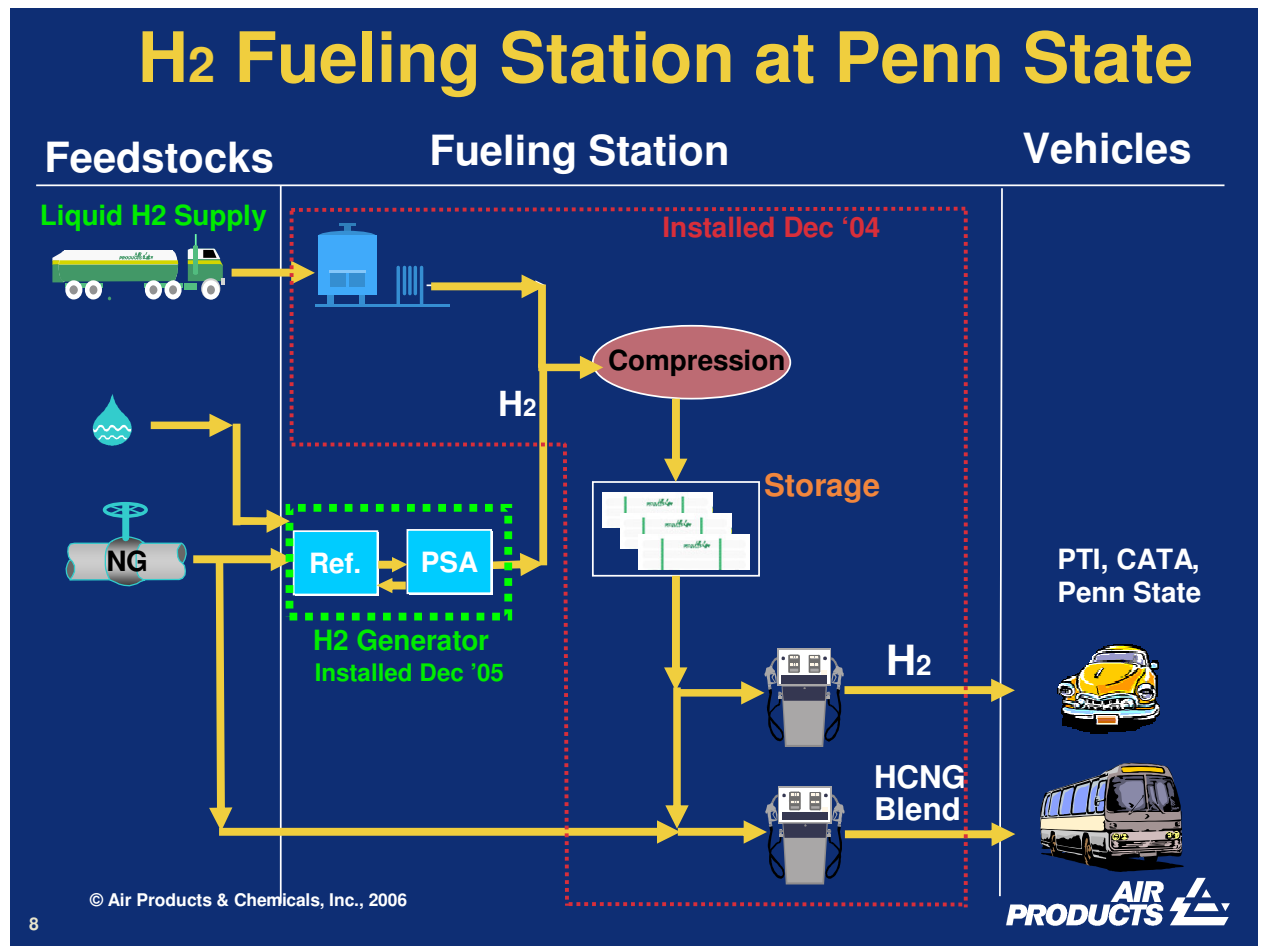

Figure 1: $\mathrm{H}_{2}$ Fueling station at Penn State

\subsection{Task Completion and Achievements}

The following provides a summary of the methods used to complete the project and the achievements of the project.

\subsubsection{Hydrogen Generator Goals and Accomplishments}

Several technologies for the production of hydrogen were evaluated, including steam methane reforming (SMR), partial oxidation of heavy oils (POX), autothermal reforming ATR, and Catalytic Partial Oxidation of Heavy Oils (CPOX). Ten quotes for commercial and noncommercial systems were evaluated, and the predicted cost of hydrogen from each reformer was determined using a discounted cash flow model in a Monte Carlo Simulation. 


\section{PRODUCTS Y $\quad$ Development of a Turnkey $\mathrm{H}_{2}$ Fueling Station}

The capabilities such as efficiency, complexity, and turnaround ratio, of the various technologies were also compared before a final design was chosen.

Air Products chose advanced SMR due to its potential to deliver the lowest cost molecule compared to the other evaluated technologies for small-scale reforming applications used in hydrogen fueling stations. The regenerative reformer offered by Harvest was chosen to service the fueling station for this particular project. The next step was to develop and improve the SMR technology, drawing from Air Products' experiences at the Las Vegas $\mathrm{H}_{2}$ Energy Station. These included:

- Optimized desulfurization, reformer, and shift catalysts

- Improved heat recovery system

- Improved efficiency

- Improved capital costs

- Improved packaging and aesthetics

- Designed for maintenance/operability

\subsubsection{Desulfurizer Design}

Three technologies for the system desulfurizer were investigated: ambient temperature adsorbents, high-temperature $\mathrm{ZnO}$, and a novel temperature swing adsorption (TSA) system. In the case of the high-temperature $\mathrm{ZnO}$ desulfurizer, $\sim 1 \%$ hydrogen from the product needs to be fed to react with the sulfur, which detracts from the total amount of hydrogen that can be produced. There were also start-up issues with this system. Consequently, the following procedures had to be implemented during start-up: some natural gas had to be purged at the beginning of start-up and the resource was wasted, or the natural gas had to be passed through the entire system, resulting in the poisoning of the reformer catalyst. In the case of the TSA design, the invention of this technology would have been too costly and complex, including purchasing the pieces of equipment required for this design. Since both simplicity and cost were priorities in choosing the system, the TSA was not chosen either. Therefore, the ambient temperature desulfurizer was chosen. Air Products developed a multi-bed system for the ambient temperature adsorbent system, in which compressed natural gas is fed into the desulfurizer system at ambient temperature and passed over the adsorbent beds. The system was also sized for the national average natural gas specification, had a 12month operating period before change-out was required, and it had sample ports $75 \%$ and $100 \%$ up the bed to monitor sulfur levels.

Two catalyst types, traditional and precious metal were evaluated for use in the shift reactor. A precious-metal, monolithic catalyst was chosen. The advantages of this catalyst were an integrated heat exchange train, maximum heat recovery and efficiency, and a low pressure drop design. Overall, the shift reactor's volume was beneficial, the unit design allowed for a faster start-up, and it was more robust.

For the heat exchange train design, the information and knowledge gathered from the on-site reformer station in Las Vegas provided the starting point of design. Several heat integration methods were evaluated. Compact heat exchangers were determined to not 
be beneficial due to the high cost and to no reduction in the production of hydrogen. The shift reactor system was optimized and integrated to improve heat efficiency, and a proprietary boiler system from Harvest was also examined. In the end, heat exchangers that were scaleable, with a cost reduction potential at scale-up production, were used.

Several vendors for the syngas compressor were investigated. Air Products chose the reciprocating air-cooled compressor design. The unit was manufactured and packaged completely by RIX, and it underwent a Machinery Engineering Design Review. All of these factors made the compressors more reliable. The unit was also more economical due to RIX's agreement to maintain spare parts at its facility and to provide availability for 24-hour delivery. Also, the use of air to cool the unit resulted in a total cost of the compressor significantly lower than that of the competitor.

\subsubsection{PSA}

A cost analysis identified that the cost of syngas separation to yield purified hydrogen was a key process step that could provide maximum return on performance and economics. This key step required a reduction in capital and operating costs, a reduction in system volume, and an increase in the recovery of the PSA system. In order to meet these goals, Air Products decided to explore, through simulation analysis and prototype testing, a PSA system developed in-house. The system that was determined to provide optimal performance included cycle adsorbent mix and cycle. Resulting in a higher hydrogen recovery with carbon monoxide contamination of less than $2 \mathrm{ppm}$ in hydrogen, with an overall hydrogen purity of $99.9999 \%$. The unit also had a lower capital cost and was maintainable. A schematic of the PSA setup used at the Penn State station is presented in Figure 2.

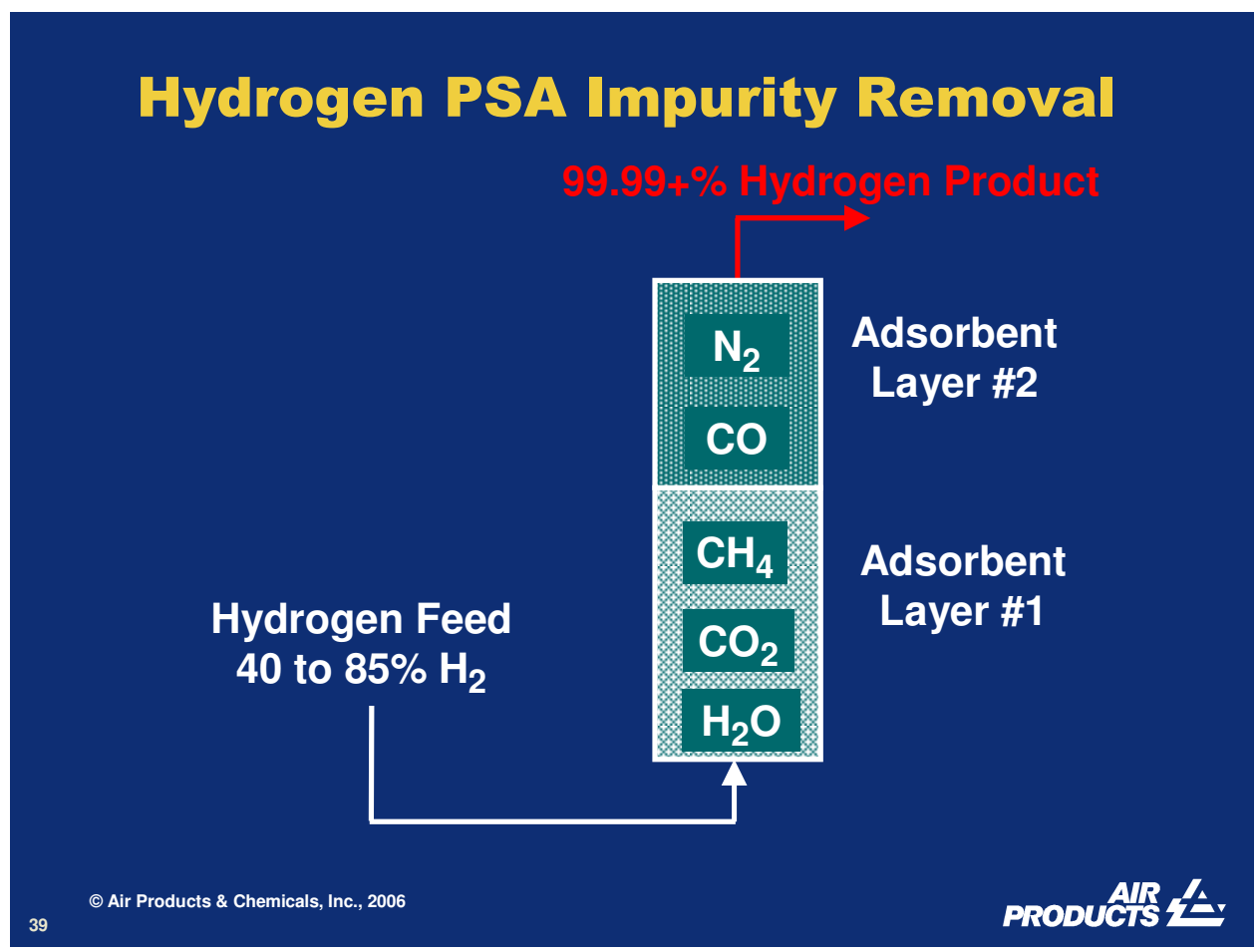


Figure 2: Schematic of PSA Setup

The design of the PSA system was established through laboratory $\left(1.4\right.$ to $\left.3.0 \mathrm{~nm}^{3} / \mathrm{hr}\right)$ and full-scale (50 to $75 \mathrm{~nm}^{3} / \mathrm{hr}$ ) prototype testing. Laboratory data were collected to establish an operating map that could be used to determine the performance expected under a range of feed gas conditions: 0.3 to $1.0 \% \mathrm{~N}_{2}, 0.3$ to $3.0 \% \mathrm{CO}, 2$ to $9 \% \mathrm{CH}_{4}$, 15.5 to $19 \% \mathrm{CO}_{2}, 68$ to $75.5 \% \mathrm{H}_{2}$ at 90 to 180 psig feed pressure and 2 to 8 psig purge pressure. For a PSA feed containing $1 \% \mathrm{~N}_{2}, 3 \% \mathrm{CO}, 5 \% \mathrm{CH}_{4}, 19 \% \mathrm{CO}_{2}, 72 \% \mathrm{H}_{2}$ at 120 psig and a waste gas at 2 psig, the PSA system utilized adsorbent vessels of 6" OD $x 5 \mathrm{ft}$ high to provide $50 \mathrm{~nm}^{3} / \mathrm{hr}$ hydrogen as a product with a $2 \mathrm{ppm}$ CO impurity level. An Air Products proprietary dynamic adsorption simulation program was used to aid in the development and design of this hydrogen PSA purification process. The simulation uses a non-isothermal, nonlinear, non-equilibrium and non-isobaric model to simulate pressure swing adsorption cycles. Features of the simulator include the ability to model the effect of multiple adsorbents in an adsorbent bed, the flexibility to describe multiple processing steps, and the ability to choose among a variety of models for adsorption isotherms and rate processes. Adsorption isotherm model parameters are determined from the experimentally measured adsorption capacity of the pure gases at 30 and $70^{\circ} \mathrm{C}$. The parameters for a mass transfer model are determined by matching breakthrough curve data. Physical property parameters for the adsorbents are determined by mercury porosimetry and pressure drop measurements. As the development of any process advances, simulation is always used in conjunction with experimental verification. The requirements for this project pushed cycle times to the lowest ever used for hydrogen purification at Air Products. The simulator was unable to predict the performance changes as on-feed time decreased from 60 to 24 seconds. Though the simulation tool is not able to accurately predict performance at varying cycle times in this range, it can be used to assess the effect of operating changes on overall system performance at a fixed cycle time.

Air Products developed two PSA prototypes: an alpha and a beta model. Tables 1 and 2 present the alpha-beta-target comparison and the alpha-beta design specification comparison, respectively.

Table 1: Alpha-Beta-Target Comparison

\begin{tabular}{|c|c|c|c|c|}
\hline Criteria & Standard PSA & Alpha Prototype & Beta Prototype & Target \\
\hline Bed Height & $20 \mathrm{ft}$ & $5 \mathrm{ft}$ & $5 \mathrm{ft}$ & $<7 \mathrm{ft}$ \\
\hline Recovery & $74-81 \%$ & $80 \%$ & $82 \%$ & $80 \%$ \\
\hline Relative Cost & 100 & 65 & 36 & 40 \\
\hline
\end{tabular}




\section{PRODUCTS 4 E. Development of a Turnkey $\mathrm{H}_{2}$ Fueling Station}

Table 2: Alpha-Beta Design Specification Comparison

\begin{tabular}{|c|c|c|c|}
\hline Criteria & Standard PSA & Alpha Prototype & Beta Prototype \\
\hline Ads Size & 1 & 0.5 & 0.35 \\
\hline Feed Time & $180 \mathrm{~s}$ & $48 \mathrm{~s}$ & $30 \mathrm{~s}$ \\
\hline \# of Valves & 16 & 16 & 2 \\
\hline
\end{tabular}

Ultimately, Air Products chose the beta model because it met all of the goals and was a better fit for the project. The cost of the PSA was two to four times less than commercially available units; the overall size was much smaller than commercially available units, and the beta prototype still met the DOE 2005 efficiency target of $82 \%$.

The beta unit uses a PSA cycle at Penn State that is unique. Initially, the gas is fed into the adsorption unit, and then the waste is blown down. Next, pressure equalization occurs in two of the units. Finally, a purge is used to remove any remaining waste. Another advantage of the beta PSA unit is the use of a rotary valve to control the flow in the PSA unit. This change in design eliminated 16 switch valves, PLC and solenoid valves, air instrumentation, and $300+$ weld joints in fabrication. These eliminations greatly reduced the footprint and cost of the PSA.

\subsubsection{Water Treatment / Cooling Water / Utilities:}

Due to the complexity of the balance of plant required to operate the reformer system, Air Products developed a utility sub-system (island) that incorporates water treatment, a cooling water system, and instrument air. This distinguishes Air Products from other reformer vendors, who place the utilities in the scope of the customer. The island that is currently used is deployable with any hydrogen generator system. It is contained within portable housing which allows the utility island to be factory constructed, thus minimizing site construction.

The wastewater treatment requirement for the Penn State site was less than the previous Las Vegas station because the reforming system operated at lower pressures. With low-pressure operation, the water treatment regulations are less stringent. Therefore, the wastewater from the low-pressure boiler required only the simple treatment of adding a water softener and passing the water through a reverse osmosis $(\mathrm{RO})$ system.

A diaphragm pump used at the Las Vegas site caused pulsations in the discharge piping and failure of a flange. To mitigate this situation, a volume vessel was installed, which added cost. To avoid these issues at Penn State, the Air Products engineers used a centrifugal pump which causes no pulsations and does not require additional volume, thus improving the overall system operation. 
The cooling water used in the system is closed-loop waste from the process trim cooler.

\subsubsection{Compression and Storage Goals and Accomplishments}

The main goals in compression and storage included improving the unit's footprint (Figure 3), aesthetics, and cost.

For hydrogen storage, steel, composites, and hydride materials were investigated. Steel was chosen to be the most effective material for use in 350 bar fueling applications.

From the economic study of reciprocating compressor, diaphragm compressor, and novel concepts for hydrogen compression, the diaphragm compressor was chosen on a total cost-to-serve basis. The reciprocating compressor required more frequent maintenance than the diaphragm compressor. The oil removal from the system could be difficult, resulting in possible contamination of the fuel fed to fuel cell vehicles. The diaphragm compressor was the optimal choice for high-purity food and dangerous oxidizer applications, requiring $40 \%$ less maintenance than the reciprocating compressor and costing $10 \%$ less. Other options that were considered, but that proved to be costly included an isothermal compressor still in development stages and a linear pump, which was not readily scaleable to the size requirement.

An Air Products Series 300 diaphragm compression system was used at the Penn State fueling station. The unit has many attributes. It is highly reliable with automated operation, it has totally integrated compression and a cascaded fueling module, and it can adapt to a variety of fleet requirements. The unit is designed to operate from any large hydrogen source (electrolysis, reformer, tube trailer, liquid tank, or pipeline). Two PDC-4-1500-7500 compressors were chosen for the Penn State application. The leadtime was short, and they could be purchased at a reasonable cost. Both compressors were $90 \%$ reliable, and the combination of two compressors on site provided a $99 \%$ probability of having one unit operational at all times; therefore, only one compressor was used at a time. The fill time of a vehicle was not affected by the number of compressors running; therefore, while the hydrogen demand on the station remained low, it created an acceptable operation schematic.

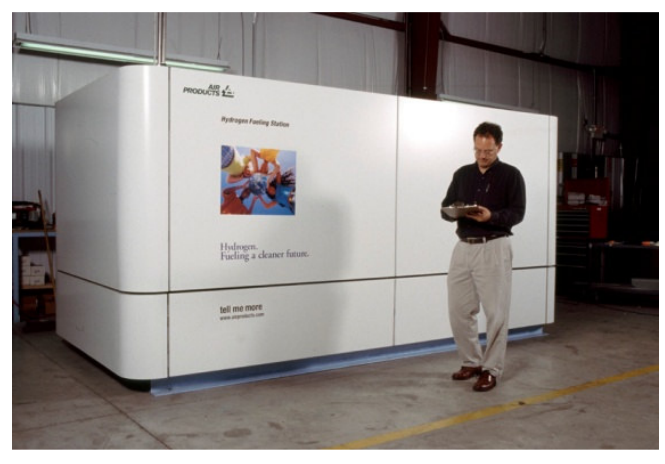

Figure 3: Compressor Footprint 


\subsubsection{Dispenser Goals and Accomplishments}

The Sacramento and Las Vegas stations were used as a starting point in the dispenser design, with a goal to design a less "industrial" and more aesthetic dispenser. Figure 4 shows the difference in designs between the "industrial" dispensers of the Sacramento and Las Vegas stations (left) and the "aesthetic" dispenser of Penn State (right). Other goals for the dispenser included validation of the accuracy of the fueling control program to fill the vehicle, improving metering alternatives and reducing system costs.

The component selection for the dispenser was completed, and the unit was constructed. It is currently good for Class 1 Div 1 electrical classification. It was also designed for high-pressure usage; the storage vessels can supply hydrogen up to 7,000 psig, and the dispenser was designed for pressures of $14,000-20,000$ psig.
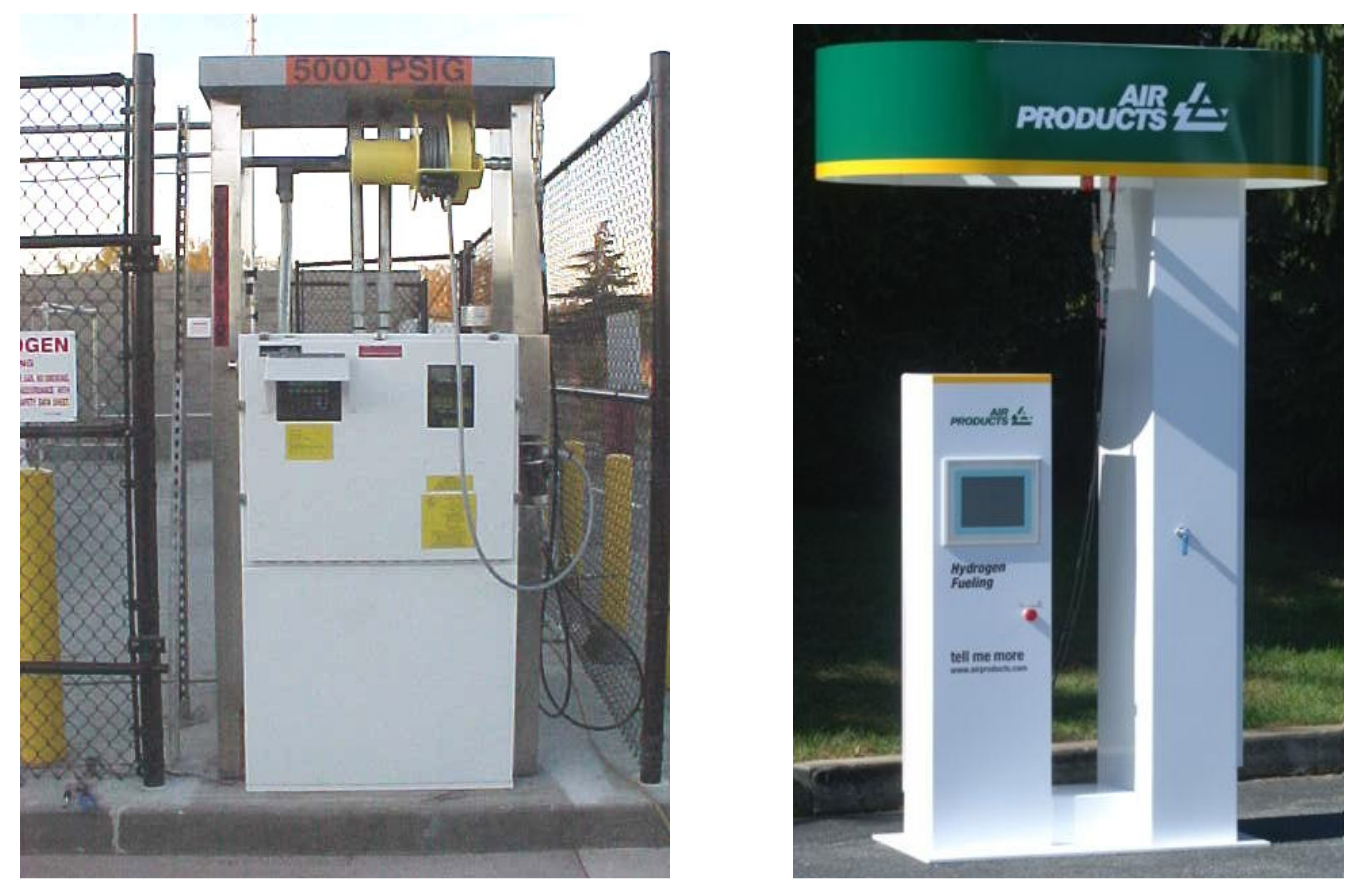

Figure 4: Dispenser Before \& After

The cost to produce the dispenser at Penn State, relative to previous ones, decreased by a factor slightly less than two. The fast-fill (generally less than 5 minutes) technology used at the station was accurate by calculation within $+/-0.2 \%$, improving the metering of the dispenser significantly during the project. Air Products is going to continue to improve metering in this area across the entire industry.

\subsubsection{Site Goals and Accomplishments}

Air Products, Penn State, and PTI (Pennsylvania Transportation Institute) chose to house the hydrogen fueling station at the compressed natural gas (CNG) vehicle fueling station. The site is located at the east end of the Penn State campus, by Beaver Stadium. The site is ideal because it is near the Pennsylvania Transportation Institute 
test track and the ECEC (Electrochemical Engine Center) where fuel cell research is conducted. These entities familiar with alternative fuels coordinated all of the necessary permitting. Air Products also worked with Penn State's own EH\&S group. The site passed NFPA 52 (National Fire Protection Agency) requirements after installation.

In October 2004 the liquid hydrogen system, hydrogen compression, hydrogen storage, hydrogen and HCNG (hydrogen and compressed natural gas) blend dispensers were installed.

\subsubsection{System Sizing and Economics}

The projected scale-up cost of hydrogen was predicted by the H2A model, which was developed by DOE. The model leverages the combined talents of industry analysts and stakeholders to improve the transparency and consistency in the approach to analyzing a multitude of hydrogen pathways. Thus, the model provides a standardized approach and set of assumptions for estimating the lifecycle cost of hydrogen production and delivery technologies and the resulting cost of hydrogen. The study determined that hydrogen could be produced at $\$ 3.05 / \mathrm{kg}$ based on a $1500 \mathrm{~kg} /$ day station with $70 \%$ utilization, and a system efficiency of $64.3 \%$. The details of the simulation are shown in Table 3.

Table 3 Simulated Hydrogen Economics

\begin{tabular}{|c|c|c|c|c|c|}
\hline & Base & HFCIT & $\begin{array}{l}\text { Large } \\
\text { Scale }\end{array}$ & $\begin{array}{c}\text { Large } \\
\text { Scale } \\
98 \% \text { Util. }\end{array}$ & $\begin{array}{l}\text { Large } \\
\text { Scale, } \\
\text { Program } \\
\text { Plan } \\
\text { Inputs }\end{array}$ \\
\hline H2 Product (kg/day) & 108 & 690 & 1500 & 1500 & 1500 \\
\hline Utilization (\%) & 70 & 90 & 70 & 98 & 70 \\
\hline Overall Efficiency (\%) & 64.3 & 64.3 & 64.3 & 64.3 & 64.3 \\
\hline Units Produced / Year & 5 & 100 & 200 & 200 & 500 \\
\hline IRR (\%) & 10 & 10 & 10 & 10 & 10 \\
\hline Power Cost (\$/kwh) & 0.05 & 0.07 & 0.05 & 0.05 & 0.08 \\
\hline NG Cost $(\$ / n m 3)$ & 0.22 & 0.16 & 0.22 & 0.22 & 0.175 \\
\hline Calc'd H2 Cost $(\$ / k g)$ & 14.01 & 2.76 & 3.08 & 2.52 & 3.05 \\
\hline
\end{tabular}

\subsubsection{System Operation}

On March 31,2006, all of the system deployment activities were completed, and the fueling station was started up and commissioned. The unit achieved the goals of 51 $\mathrm{nm}^{3} / \mathrm{hr}$, meeting the $50 \mathrm{~nm}^{3} / \mathrm{hr}$ specified by DOE. The overall efficiency goal of $65.1 \%$ was also achieved during a full performance test in the summer. During the beginning of the operating period, an $\mathrm{H} 2 \mathrm{~A}$ analysis was run and it was shown that a scaled-up 


\section{PRODUCTS 4 E. Development of a Turnkey $\mathrm{H}_{2}$ Fueling Station}

hydrogen production fueling station could produce hydrogen at a cost of $\$ 3.05 \mathrm{gge}$. This met the DOE goal for competitive hydrogen production.

The operation of the station has proved to be an invaluable learning experience. During the 17-month operating period, opportunities to optimize the equipment, improve control systems on the PSA, improve the $\mathrm{CO}$ analyzer system, and mitigate sulfur poisoning were encountered.

A major challenge occurred in the operation of the facility in the summer of 2006. In July 2006, the hydrogen generator was shut down due to a reduction in the reformer catalyst activity. In August 2006, the damage to the reformer catalyst was determined to have been caused by a sulfur breakthrough. The desulfurizer had broken down at about $50 \%$ of the expected capacity. The desulfurizer vendor brought in a fresh supply of adsorbent and replaced the compromised material. Air Products then began to steam the reformer catalyst at the recommendation of the catalyst vendor, a technology group within Air Products, and Harvest Energy Technology. After two months of unsuccessful removal of the sulfur contaminating the catalyst, Air Products removed the tainted reformer catalyst and replaced it. The entire process of cutting into the reformer, removing the contaminated catalyst, loading fresh catalyst, and welding the reformer again took about two days. The catalyst was revised, a guard bed installed and the unit operated as expected thereafter.

As of March 31, 2007, the $\mathrm{H} 2$ Generator logged a total of 4225 operating hours. The major challenges and improvements to the $\mathrm{H}_{2}$ generator system involved the following:

- Determining the best way to mitigate sulfur poisoning of the reformer catalyst.

- Developing a replacement technique for the reformer catalyst onsite, rather than shipping the reformer to a repair location, saving $\$ 40,000$ to $\$ 50,000$ dollars.

- Installing a desulfurizer guard bed to provide an additional layer of protection from sulfur to the reformer catalyst.

- Implementing continual monitoring of the reformer system for sulfur breakthroughs.

- Improving advanced controls on the PSA.

- Improving the $\mathrm{H}_{2}$ Product Analyzer system, resulting in more consistent $\mathrm{CO}$ in the $\mathrm{H}_{2}$ readings.

To date, all of these challenges have been properly addressed and resolved in order to improve the overall infrastructure of the hydrogen station. 


\section{PRODUCTS 4 E Development of a Turnkey $\mathrm{H}_{2}$ Fueling Station}

\section{PSU Vehicle Program}

During 2003, a separate project, not funded by the DOE, was initiated that assisted in the development and management of the Penn State station. This project involved fueling a hydrogen fleet of vehicles at the station with a sufficient hydrogen demand to place a significant load on the steam methane reformer to keep it in continuous operation. This load required a consumption of $40-100 \mathrm{~kg}$ a day. A partnership including Penn State Hydrogen Vehicle Research Laboratory (HHVRL) and its Office of Physical Plant (OPP), Air Products, Capital Area Transportation Authority (CATA), Collier Technologies, and Columbia Gas began meeting to explore the opportunity of fielding a hydrogen fleet. During the same year, the partnership proposed the hydrogen fleet project to the Pennsylvania Department of Environmental Protection (PDEP) under the Energy Harvest Grant, requesting funding to complete three HCNG bus conversions, eight HCNG vans, a fuel cell vehicle and H2ICE (hydrogen engine) hybrid vehicle developed by HHVRL. These vehicles were to be put in operation for a total of three years at a project cost of about $\$ 3,200,000$. HCNG conversion included modifying natural gas engines to accept a blend of both hydrogen and natural gas. An emphasis was placed on the bus conversion, since HCNG blends in a bus typically consume more hydrogen than does fueling a single passenger vehicle with only hydrogen. With patented technology, Collier Technologies converted the natural gas engines of the Penn State vehicles to consume $30-50 \%$ blends of hydrogen by volume with natural gas. Also, at the time, vehicles of this nature were much less expensive to obtain than were fuel cell vehicles, since Penn State already had a fleet of natural gas engines.

The vehicles were deployed in two phases. The Phase I fleet consisted of one HCNG bus, one HCNG van, and a fuel cell vehicle and was funded jointly by PDEP and the Pennsylvania Department of Community and Economic Development (PDCED) in 2004. The same organizations funded Phase II, which included six additional HCNG van conversions and a H2ICE hybrid vehicle in 2005. The HCNG vans were operated by Penn State OPP for campus maintenance, and the HCNG transit buses were operated by CATA on campus routes. The fuel cell vehicle and H2ICE hybrid vehicle were managed on campus, as well. Figure 5 pictures the fuel cell vehicle (left) and one of the HCNG vans (right) at the Penn State station. Figure 6 is a photograph of the CATA transit bus that was converted to HCNG technology for the project. 


\section{PRODUCTS Y $\quad$ Development of a Turnkey $\mathrm{H}_{2}$ Fueling Station}

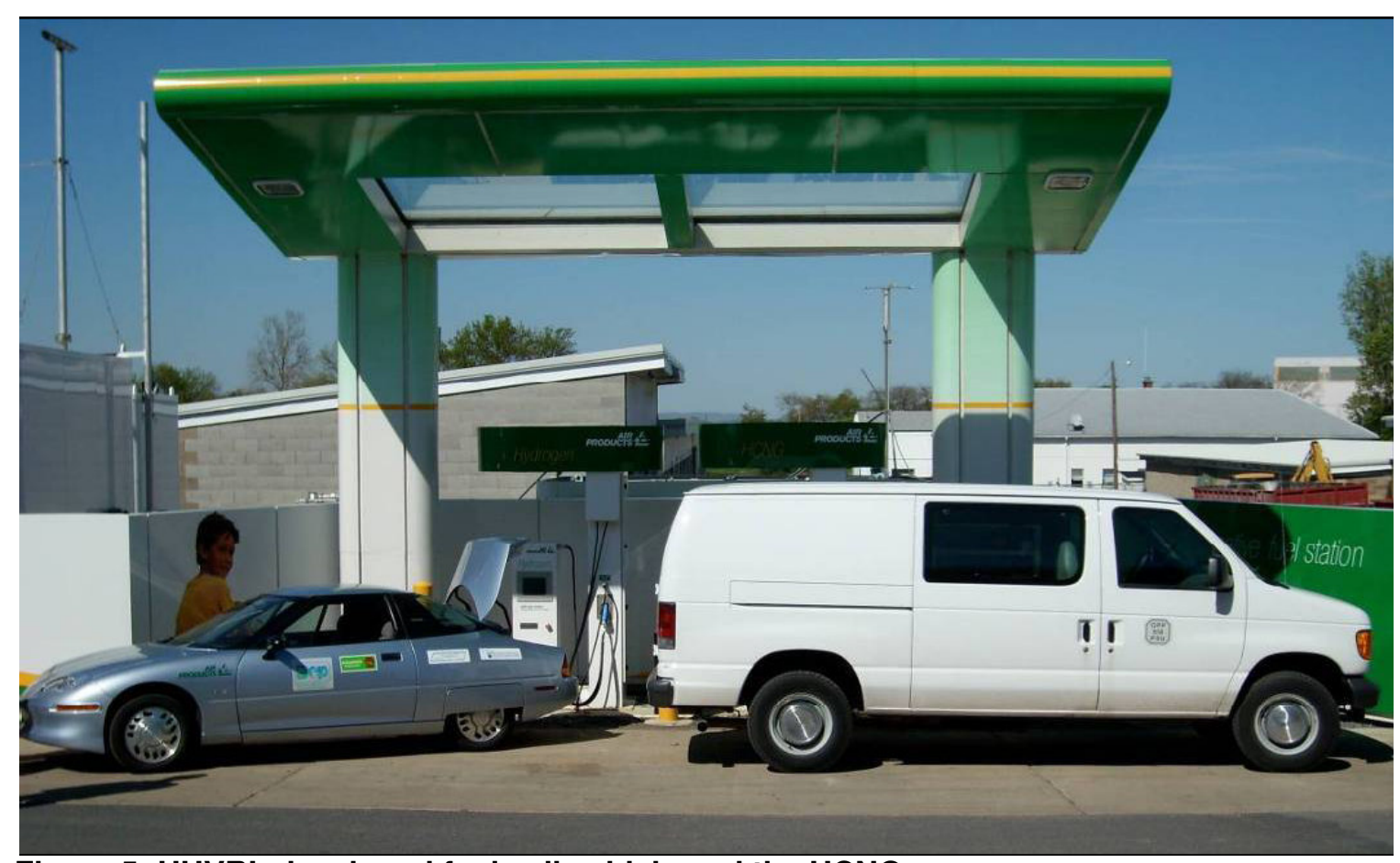

Figure 5: HHVRL developed fuel cell vehicle and the HCNG van

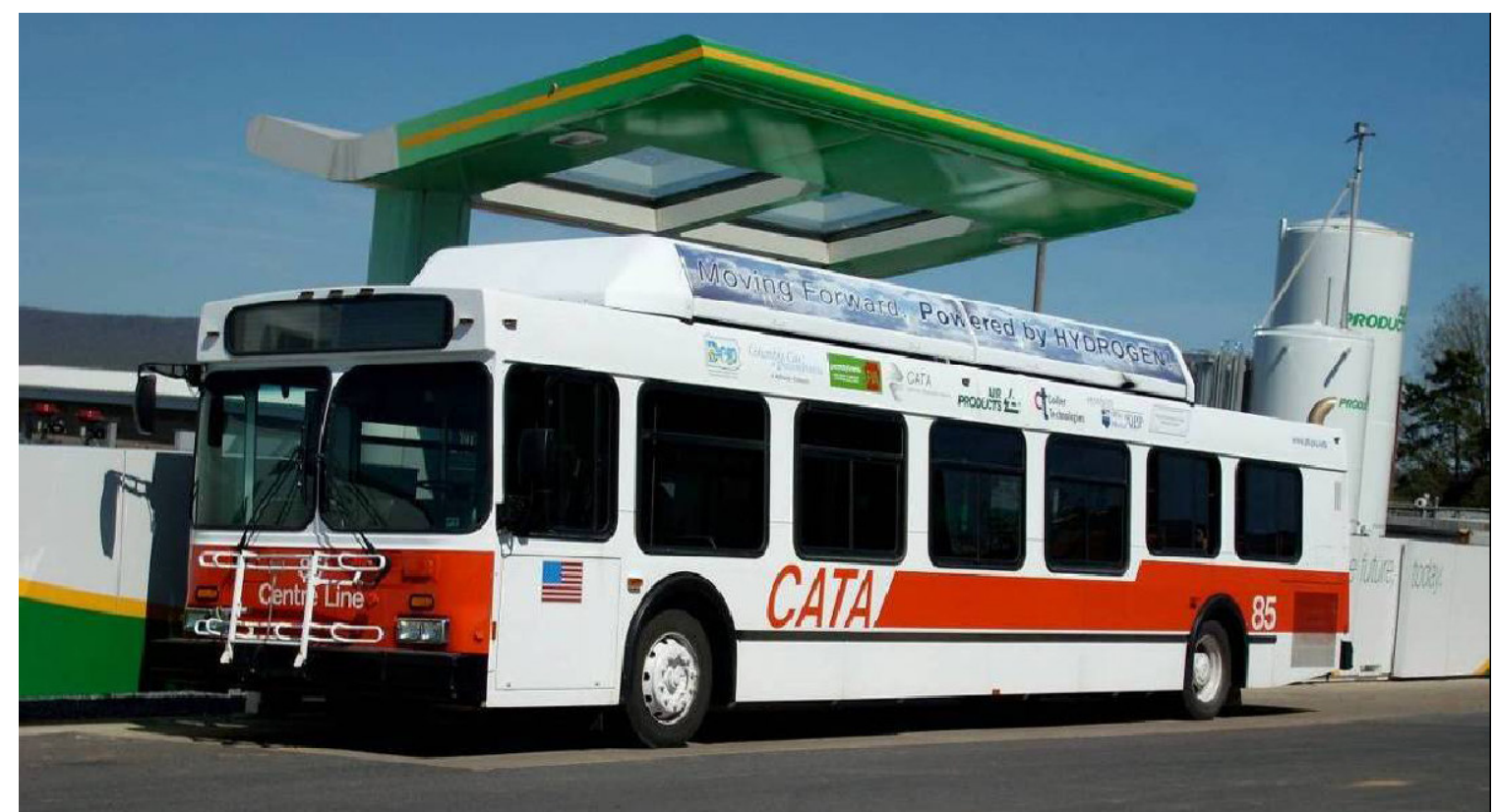

Figure 6: HCNG transit bus at the Penn State station

Fueling of the vehicles and collection of operational data from the Penn State station began in 2007. The total number of fuelings at the station for that year was 75 .

Operational statistics from early 2008 showed the total number of fuelings so far is 23 . Table 4 summarizes the estimated hydrogen demand for each vehicle of the proposed fleet, including statistics from several researchers on campus who transport portable 
laboratory tanks between their labs and the station to fill the tanks with hydrogen or HCNG for testing and research purposes. Although the table reveals an estimated hydrogen demand of $13.5 \mathrm{~kg} \mathrm{H}_{2}$ /day, the process of converting two more transit buses as originally planned is underway, which will bring the demand to about $40 \mathrm{~kg}$, or the calculated goal per day. Fueling at the station provides the opportunity to gain valuable field experience with on-site producing technology, and it provides long-term data on both the hydrogen station and the vehicles operated with either hydrogen or HCNG technology. This data will allow the opportunity for further research on both the station and the hydrogen vehicles, in order to provide solutions that can improve the overall operations of both.

Table 4: Estimated Hydrogen Demand of Current Fleet

\begin{tabular}{|l|c|c|c|c|}
\hline Vehicle Type & $\begin{array}{c}\text { Hydrogen } \\
\mathrm{kg} / \mathrm{fill}\end{array}$ & \# of Vehicles & $\begin{array}{c}\text { Vehicles } \\
\text { Fills/day }\end{array}$ & $\begin{array}{l}\text { Demand } \\
\mathrm{kg} / \text { day }\end{array}$ \\
\hline HCNG Bus & 8.9 & 1 & 1 & 8.9 \\
\hline HCNG van & 2 & 7 & .2 & 2.8 \\
\hline Fuel Cell & .62 & 1 & 2 & 1.24 \\
\hline H2ICE Hybrid & .62 & 1 & .5 & .31 \\
\hline $\begin{array}{l}\text { Research } \\
\text { Tanks }\end{array}$ & 1.0 & N/A & .2 & .2 \\
\hline Total & - & 10 & 3.9 & $\sim 13.5$ \\
\hline
\end{tabular}

\section{$5 \quad$ Publications and Presentations}

- DOE Annual Review Meeting - 2002-2005

- DOE Regional Meeting in Annapolis, MD - 2004

- NHA Annual Meeting - March 2005

- SAE Annual Meeting - 2004

- DOE Technical Team Review at Penn State - February 2006

\section{Products Developed}

During the refueling project, two patents were developed. The patent titles, authors, numbers, and dates are presented in Table 5.

Table 5: Patents

\begin{tabular}{|c|c|c|c|}
\hline Patent Title & Author(s) & $\begin{array}{c}\text { Patent } \\
\text { Number }\end{array}$ & $\begin{array}{c}\text { Date } \\
\text { Issued }\end{array}$ \\
\hline $\begin{array}{c}\text { Rotary Sequencing Valve with Flexible } \\
\text { Port Plate }\end{array}$ & G. P. Wagner & $6,889,710$ & $\begin{array}{c}\text { May 10, } \\
2005\end{array}$ \\
\hline $\begin{array}{c}\text { Multilayered Adsorbent System for } \\
\text { Gas Separations by Pressure Swing } \\
\text { Adsorption }\end{array}$ & $\begin{array}{c}\text { T. C. Golden } \\
\text { E. L. Weist } \\
\text { J. R. Hufton } \\
\text { P. A. Novosat }\end{array}$ & $6,893,483$ B2 & $\begin{array}{c}\text { May 17, } \\
2005\end{array}$ \\
\hline
\end{tabular}




\section{PRODUCTS Y $\quad$ Development of a Turnkey $\mathrm{H}_{2}$ Fueling Station}

\section{Conclusions}

Air Products succeeded in creating a turnkey fueling station that met the needs of Penn State. This utility island was constructed, installed with ease, and proves to be reliable, operable, and viable. The project targets were also fulfilled. Based on field data analysis, it was determined by the H2A model that hydrogen produced from the station at a rate of $1500 \mathrm{~kg} /$ day would be able to deliver the hydrogen at a price of $\$ 3.05 / \mathrm{kg}$ gge. The station's efficiency was measured to be $65.1 \%$, the PSA was tested and ran at an efficiency of $82.1 \%$, and overall the utility system performed with $70 \%$ utilization, thus meeting the project targets. Air Products was also able to successfully and safely fuel a hydrogen fleet of vehicles operated on the Penn State campus a significant number of times. As a result, Air Products gained valuable field experience with an onsite methane reformer and with both hydrogen and HCNG fueling, which allows for further research in finding solutions to improving the overall infrastructures of hydrogen technology. However, much research is still needed for future fuel station applications.

Further research must be performed in order to create the corner gas station that has the capability to produce $1500 \mathrm{~kg} /$ day of hydrogen. If SMR technologies are to be used, roughly 17,000 square feet of total space for the entire system with auxiliaries will be required, and some of the structures could be as tall as three stories. These requirements make it unlikely that the average corner fueling station could be converted to support a typical full scale, former-based retail station. Another factor that must be considered is the ability of an SMR station to meet peak requirements. Figure 7 shows the average station fuel usage (for gasoline) on a weekly basis. The peak station usages are at midday. In order for the SMR station to meet the required $70 \%$ station utilization, nearly $2000 \mathrm{~kg}$ of storage are required. This volume of storage may not be feasible in the corner fuel station application. Another challenge in meeting the peak requirements with the steam methane reformer is the ability to match the demand profile of the reformer required for the technology to run safely and efficiently. Meeting the demand profile will reduce the potential hazards associated with the reformer, including possible overheating, and will make the cost of managing the reformer more favorable. However, approaching this demand requires a fairly consistent amount of fueling on a day-to-day basis. In real-life applications, the amount of fueling completed at a station is inconsistent and random. There may be days at the station during which the total amount of fueling is not sufficient to keep the reformer at the peak requirement for optimal performance. Therefore, another obstacle is finding solutions to minimize the cost and manage the operations of the reformer, once the station becomes public and accessible to any customer as a typical corner fuel station. Finally, in order to make the economics of producing SMR fueling stations feasible, a very large number of stations would have to be constructed. More research on footprint, turndown capability and long term reliability must be performed to determine how to make the SMR fueling stations a feasible station design. 


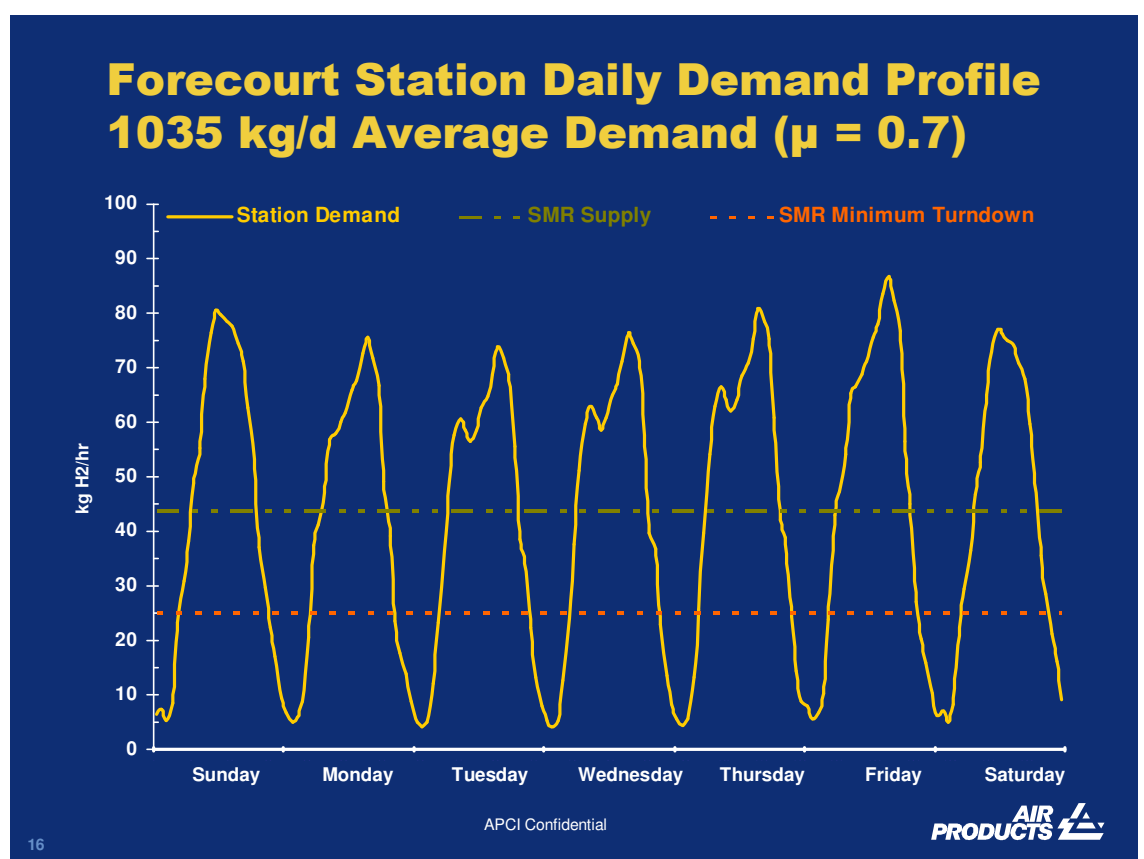

Figure 7: Average Station Fuel Usage Weekly

Two alternative station designs could be used to replace an on-site distributed hydrogen-generating station design. Stations that utilize a liquid hydrogen supply would be suitable for hydrogen fueling, particularly since their footprint (8000 to $9000 \mathrm{sq} f \mathrm{ft}$ ) is significantly smaller and the cost of the hydrogen is less than SMR-produced hydrogen at smaller utilization rates (see Figure 8). Stations supplied by a hydrogen pipeline require the smallest amount of space (7000 sq ft) and they, too, dispense less expensive hydrogen at lower utilization rates.

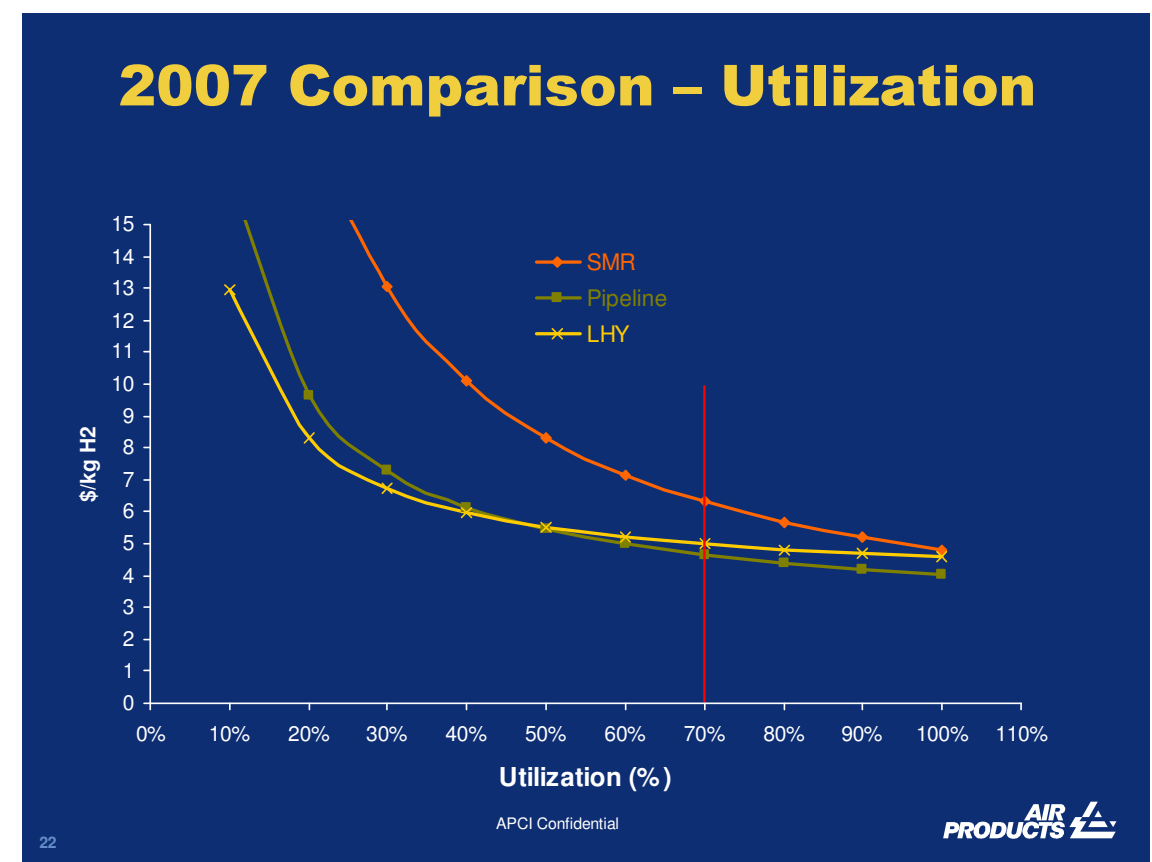

Figure 8 Utilization Rates 2007 
More research and practical studies as previously noted on the most appropriate means to supply hydrogen must be performed before hydrogen can be feasibly implemented as a fuel. This work will happen only if Government incentives and policies are implemented to drive the transition to hydrogen as an alternative fuel. 